\title{
A Corpus-based Study of Conjunctive Adjuncts in the Writings of Native and Non-native Speakers of English
}

\author{
Saud K Mudhhi ${ }^{1} \&$ Riyad F Hussein ${ }^{2}$ \\ ${ }^{1}$ Arab Open University, Kuwait \\ 2 Dept. of Linguistics, Faculty of Foreign languages, University of Jordan, Amman \\ Correspondence: Riyad F Hussein, Dept. of Linguistics, Faculty of Foreign languages, University of Jordan, Amman. \\ E-mail: rfhussein@hotmail.com
}

Received: July 5, 2014

Accepted: July 22, 2014

Online Published: August 18, 2014

doi:10.5430/elr.v3n2p18

URL: http://dx.doi.org/10.5430/elr.v3n2p18

\begin{abstract}
This study explored the use of conjunctive adjuncts by Kuwaiti EFL learners and native speakers of English. It investigated the frequency of occurrence of conjunctive adjuncts in the writings of Kuwaiti EFL learners and native speakers of English. It also attempted to find out the frequency of the semantic categories of conjunctive adjuncts such as additive, contrastive, causal, temporal and continuatives in KLC and NSC. Finally, it aimed to find out the overused and underused conjunctive adjuncts in the two corpora.

To achieve the goals of this study, we utilized two language corpora. The first consisted of essays collected from Michigan Corpus of Upper-level Student Papers and the second was compiled by the researchers. Forty essays written by Kuwaiti EFL learners enrolled at Kuwaiti universities were then collected, classified and analyzed.

Results of this study showed that Kuwaiti EFL learners overused conjunctive adjuncts, namely, additives and causals. Native speakers of English used adversatives frequently. However, Kuwaiti EFL learners did not use the various types of conjunctive adjuncts as native speakers did. In addition, the results showed that Kuwaiti EFL learners overused certain conjunctive adjuncts such as in addition, for, and but and underused certain conjunctive adjuncts such as however, though and also.
\end{abstract}

Keywords: Conjunctive adjuncts, Conjunctions, Corpora, Native speakers, Non-native speakers, Michigan Corpus, Writing

\section{Introduction}

Cohesion was first introduced by Halliday \& Hasan (1976) and then encouraged by many scholars and linguists to study the cohesive devices, both lexical and grammatical, in written discourse. There are several types of cohesive devices, one of them is conjunctive adjuncts. They are used to link the text semantically and logically. Many English as a foreign language (EFL) learners find conjunctive adjuncts difficult to master because of numerous factors such as the nature of these devices which are optional (Biber, Johansson, Leech, Conrad \& Finegan, 1998). EFL learners find it difficult to decide when to use them. In addition, conjunctive adjuncts are various and their usage depends on students' language proficiency and the type of register e.g., news and conversation. In other words, their usage depends on different communicative functions. For example, in scientific register, conjunctive adjuncts such as therefore and consequently, which are rarely used in informal conversation to express cause and effect relationships, are commonly required to be used. Another factor is that learners' first language may cause linguistic interference that influences learner's choice of conjunctive adjuncts. Finally, many EFL learners may either underuse or overuse some conjunctive adjuncts (Altenberg and Tapper, 1998; Crewe, 1990).

The rise of corpus-linguistics as a new linguistic field that studies the naturally occurring language elements by using a large amount of authentic data has helped researchers and linguists to investigate many language aspects such as conjunctive adjuncts, their linguistic properties and their frequency of occurrence. The corpus generally refers to texts that are taken from authentic materials such as news, reports, literary texts, conversations and academic papers.

Many studies were conducted on the use of conjunctive adjuncts in the writings of Arab EFL learners such as Bacha and Hanania (1980), Khalil (1989), Khuwaileh and Shoumali (2000), Hinkel (2001), Fakhra (2009) and Abu Sharkh (2012). These studies proved that Arab EFL learners encounter challenges in the use of conjunctive adjuncts in their 
writings. To fill this gap, we aimed to investigate the use of conjunctive adjuncts in the writings of Kuwaiti EFL learners compared to the writings of native speakers.

\section{Review of Literature}

Halliday \& Hasan (1976) used the term cohesion to refer to how the text is presented in a logical and connected way. They argued that cohesion is based on lexical and grammatical relationships that make sentence sequences as connected discourse and are to a great extent realized by the application of various types of 'cohesive ties' which are categorized into five major categories: reference, substitution, ellipsis, conjunction, and lexical reiteration and collocation. They produce a logically and syntactically well connected piece of writing.

Thus, it is worthwhile to shed light on the difference between the cohesive conjunctions that Halliday \& Hasan (1976) refer to as conjunctive adjuncts and the structural conjunctions since some writers may not distinguish between the meaning of conjunctions and conjunctive adjuncts. They argued that conjunctions have two ways of functioning in discourse: 'structurally' and 'cohesively'. They are structural when indicated by a coordinator or subordinator connecting two linguistic units within the sentence. On the other hand, they operate cohesively only when indicated by a connective expression - normally distinct from coordinator and subordinator expressions, and usually functioning as 'Adjunct- 'establishing connection between two separate sentences.

In addition, Bloor and Bloor (1995) point out that the distinction between conjunctions and conjunctive adjuncts "can be a source of some confusion." (p. 56) Conjunctions can be categorized into two types: coordinators e.g., (and, but, so, for, yet, or) and subordinators e.g., (though, although, if, whether, while). Conjunctive adjuncts are considered as a function in the clause like subject or verb in the clause. In other words, they argued that because conjunctions, syntactically speaking, are not part of the structure of the clause, for they do not belong to either of the clauses they join, and because they have a semantic function - in addition to the grammatical one - signaling logical relationships between (the clauses or phrases) they connect, they are sometimes classified according to the meaning or logical-semantic relations they indicate as well. These relations are addition, adversity, alternation, time succession, and contrast.

In addition, Eggins (2004) distinguished conjunctive adjuncts from structural conjunctions. While conjunctive adjuncts construct semantic ties between meanings that are not in the same clause, structural conjunctions express structural relationships between clauses within a single sentence.

Fakhra (2009) investigated conjunctive adjuncts in the writings of Syrian students who study English at the university level in comparison to native speakers of English. She used the corpus-based approach in her study. The corpus included literature essays written by Syrian students. In addition, she used another corpus written by British students. The findings showed the total frequency of occurrence of conjunctive adjuncts in the two corpora was significantly different. Syrian students used almost twice as many conjunctive adjuncts in comparison to the British students, particularly causal and additive adjuncts. In addition, it was found that the British students used more different types of conjunctive adjuncts than the Syrian students.

Abu Sharkh (2012) investigated the use of conjunctive adjuncts among three groups of Palestinian students at the college level. He found that additive adjuncts were overused by the beginners and intermediate learners, especially the additive 'and'. He also found that the least used conjunctive adjuncts were causal and temporal among the three groups. They also underused other conjunctive adjuncts.

Granger and Tyson (1996) compared a sample of the French mother tongue sub-component of the ICLE (International Corpus of Learner English) corpus with a sample of writing from the control corpus of English essay writing. They found that there are overused individual connectors (e.g., actually, indeed, of course, moreover, e.g., for instance) and others underused (e.g., however, instead, though, yet, hence, then) in the French corpus. They found:

Even at a reasonably advanced level, connectors are difficult to master; we have seen that French learner connector usage differs widely from that of their native speaker counterparts: this is due to an inability to differentiate stylistically, insufficient knowledge of semantic restrictions placed on individual connectors, and inexperience in manipulating connectors within the sentence structure (pp. 24-25)

Tapper (2005) studied how advanced Swedish EFL learners used connectives in argumentative essays in comparison to American university students. Data were taken from different sources, the International Corpus of Learner English (ICLE): the Swedish sub-corpus and the control corpus which consisted of essays written by American university students. Results showed the advanced Swedish EFL learners overused adverbial connectives compared to American university students. Slightly more types of connectives were used by Swedish learners than American students. 
Swedish used the contrastive followed by resultative, clarifying, and additive relations. They also used different kinds of connectives to express the same coherence relations.

Ishikawa (2009) conducted a study on the English linking adverbials in the writings of Asian learners. The researcher used the International Learner Corpus by English native speakers and Asian non-native speakers, Japanese learners of English (JLE) and Chinese (CLE). The findings showed a gap between native speakers and non-native speakers in the use of linking adverbials in essay writing. Asian non-native speakers overused additive types of linking adverbials and linking adverbial items concerning the introduction of additional information and intensification of meaning, but underused the introduction of parallel information and sequential introduction of information. Unlike native speakers of English, Japanese and Chinese learners of English used major linking adverbial items in their own ways, which may be attributed to their first language.

\section{Objectives}

The main purpose of this study was to find out the frequency of occurrence of conjunctive adjuncts in two corpora, namely the writings of Kuwaiti learners of English (hereafter KLC) compared to the writings of native speakers of English at Michigan University (hereafter NSC) and the variety of conjunctive adjuncts in both corpora. Second, the study aimed to find out the frequency of the semantic categories of conjunctive adjuncts such as additive, contrastive, causal, temporal and continuatives in KLC and NSC. Finally, it aimed to find out the overused and underused conjunctive adjuncts in the two corpora. More specifically, the study was informed by the following questions:

1. What is the overall frequency of occurrence of conjunctive adjuncts in KLC and NSC?

2. What is the frequency of each semantic category in KLC compared to NSC?

3. What are the overused and underused conjunctive adjuncts in KLC compared to those used in NSC?

\subsection{Significance of the study}

This study may enrich the corpus-based studies of English in the Middle East and help other researchers and English teachers in understanding the conjunctive adjuncts in the writings of non-native and native speakers of English and how they are used by both groups of students. This research may also be of some benefit to other researchers who may utilize a corpus-based approach to study or investigate language-related problems such as conjunctions, phrasal verbs, collocations or idioms in English.

\section{Study Corpus}

The data for this study was collected from the writings of learners of English as a foreign language in Kuwaiti universities (University of Kuwait and Arab Open University- Kuwait Branch). In addition, it included writings of native speakers of English. These writings were taken from the Michigan Corpus of Upper-level Student Papers (MICUSP). So, there were two corpora used in this study. The first one consisted of 40 essays written by the junior and senior students majoring in English in Kuwaiti universities. The essays were classroom assignments written by junior and senior students on English language and literature. The students were given unlimited time and were allowed to use language references such as dictionaries and grammar books.

The second corpus was Michigan Corpus of Upper-level Student Papers where the researchers chose 25 essays written by native speakers of English about English and linguistics topics and was of good quality because most essays were graded A. It may be unfair to compare the quality of EFL writings with that of native speakers but the focus in this comparison is not the quality of writing but rather the types and frequency of conjunctive adjuncts used. The difference in the number of essays included in the corpus is due to their length. However, the total number of words or tokens in KLC was 94418 and in NSC was 95538.

We measured the lexical density of each corpus through type-token ratio. This ratio is calculated through dividing the total number of types by the total number of tokens. Tokens are all the words in a passage while types are words which are different from each other.

Table 1. Type-token ratio of lexical density in KLC and NSC

\begin{tabular}{lll}
\hline Corpus & KLC & NSC \\
\hline Total number of tokens & 94.418 & $\mathbf{9 5 . 5 3 8}$ \\
Total number of types & 8.467 & $\mathbf{1 1 . 3 5 9}$ \\
Type-token ratio & $\mathbf{8 . 9}$ & $\mathbf{1 1 . 8}$
\end{tabular}

Table 1 shows that NSC is denser with lexical items than KLC as the type-token ratio for NSC is 11.8. This means 
the variation of lexical items in the writings of native speakers is more than that in the writings of Kuwaiti learners of English.

\subsection{Methods of data analysis}

The MonoConc Pro software was used to investigate the corpus data. After identifying the frequency of occurrence of each conjunctive adjunct in both corpora, we used raw frequencies and percentages to analyze the findings.

For analyzing conjunctive adjuncts in both corpora, the scheme of Halliday \& Hasan (1976, see Appendix A) was used due to the simplicity, clarity, and comprehensiveness of its conjunction classification. This scheme consists of five types of conjunctive adjuncts. They are additive (e.g., in addition, furthermore, besides), adversative (e.g., yet, though, however, nevertheless), causal (e.g., hence, therefore, for this purpose), temporal (e.g., after that, at last, first, in short) and continuative (e.g., now, of course, after all).

The MonoConc Pro software is valid and suitable for investigating the conjunctive adjuncts as it was used in many similar studies. One of them is Patanasorn (2010) who studied the use of linking adverbials in a Thai English learner corpus. In addition, this instrument is excellent as a means of analyzing corpora and producing a key word in context (KWIC) and frequency statistics for the target word. It is also valued as a tool for searching how language is used in natural settings, thus providing valuable resources for both teachers and researchers (See Reppen, 2001). In terms of reliability, we piloted the instrument on five essays written by Kuwaiti EFL learners where the conjunctive adjuncts used in these essays were analyzed by MonoConc Pro.

\section{Results and discussion}

This study explored the use of conjunctive adjuncts by Kuwaiti EFL learner sand native speakers of English and investigated the frequency of occurrence in their writings. It also investigated the frequency of semantic categories of conjunctive adjuncts in KLC and NSC corpora. Finally overused and underused conjunctive adjuncts in both corpora were investigated. This was achieved through a corpus-based approach. Following were the study questions and their results. Findings were reported with reference to the theme questions listed above to make it easier for the reader to follow the discussion and interpretation of results.

5.1 Findings related to the first question: What is the overall frequency of occurrence of conjunctive adjuncts in KLC and NSC?

In order to measure the overall frequency of occurrence of conjunctive adjuncts in KLC and NSC, we calculated the total number of words in each corpus and the rate of occurrence of conjunctive adjuncts. The number of words in KLC was 94418 and the number of conjunctive adjuncts was 1577 . So, the percentage of their frequency of occurrence is $1.67 \%$ whereas the number of words in NSC was 95538 and the number of conjunctive adjuncts was 915 , so the percentage of frequency of occurrence of conjunctive adjuncts is $0.95 \%$

From the above, it is obvious that there is a noticeable difference in the frequency of occurrence of conjunctive adjuncts in KLC and NSC. The conjunctive adjuncts are more frequently used in KLC than in NSC.

With regard to the variety of the conjunctive adjuncts used in both corpora, it was necessary to find out the number of different conjunctive adjuncts along with their frequencies in both corpora in order to make a typology of the conjunctive adjuncts used by each group and compare their clustering. To find out the number of conjunctive adjuncts in the writings of each group, type-token ratio (TTR) was calculated by dividing the total number of different conjunctive adjuncts by their overall occurrence as shown in Table 3. A low-type token ratio indicates the use of relatively fewer types of conjunctive adjuncts with more repetition of each one, whereas a high-type token ratio indicates the use of relatively higher number of conjunctive adjuncts with less repetition of each one. The general norm of this measuring method can be put as follows: a low type-token ratio indicates that there are conjunctive adjuncts which are repeated many times, and a high type-token indicates a greater number of conjunctive adjuncts which are repeated less.

Table 2. The variety ratio of conjunctive adjuncts in both corpora

\begin{tabular}{lll}
\hline & KLC & NSC \\
\hline Number of different conjunctive adjuncts & 64 & 65 \\
Number of conjunctive adjunct tokens & 1577 & 915 \\
Type-token ratio (TTR) & $4.1 \%$ & $7.1 \%$ \\
\hline
\end{tabular}

Table 2 shows that there is a noticeable difference in type-token ratio in both corpora. It was $7.1 \%$ In NSC and $4.1 \%$ 
in KLC (though the number of different conjunctive adjuncts is almost the same in both corpora. This means that the KLC included types of conjunctive adjuncts which were repeated many times while the NSC consisted of more types of conjunctive adjuncts with less repetition of each one.

The findings of the first question revealed that the Kuwaiti EFL students overused conjunctive adjuncts in comparison to native speakers' use. The percentage of the occurrence of conjunctive adjuncts in the whole corpus of $\mathrm{KLC}$ was $1.67 \%$ while the percentage of the occurrence of conjunctive adjuncts in NSC was $0.95 \%$.

These findings are consistent with Hinkel (2001) who found that conjunctive adjuncts were used by all non-native groups at significantly higher median frequency rates than those of native speakers. This finding also was reaffirmed by Fakhra (2009) who found that Syrian students used almost twice as many conjunctive adjuncts in comparison with the British students. In addition, Tapper (2005) found that advanced Swedish EFL learners overused conjunctive adjuncts compared to American university students. The overuse of the conjunctive adjuncts in the writings of non-native speakers may be related to two factors as suggested by Crewe (1990). The first is that students try to impose surface logicality on their writings where there is no need to deep logicality. The second factor is that the overuse of conjunctive adjuncts might be seen as a way of disguising poor writing as writers try to overcome an area of difficulty by the abundance of superficial links.

The answer to the second part of this question relates to the relationship between the variation of conjunctive adjuncts and the quality of good writing. The reason for this question is that high variety is an indicator of good quality writing, and that the good writers' (represented by the native speakers' writings) texts would be characterized by a relatively high conjunctive adjunct variety. This would also reveal whether all types of conjunctive adjuncts included in the analysis were used in all writings. The type-token ratio of the conjunctive types showed that the Kuwaiti EFL students use few conjunctive adjunct types - 4.24\% compared to the native speakers who exhibited variation in their use of the conjunctive adjuncts- $7.43 \%$. Results of this part of this question confirm what other researchers found. For example, Fakhra (2009) found that British students used different types of conjunctive adjuncts more than the Syrian students. Also, Tanko (2004) found that foreign learners use fewer types of conjunctive adjuncts than the native speakers. The results are also consistent with Patanasorn (2010) who found that there is a higher number and a wider range of conjunctive adjuncts in the more effective essays. However, the results are consistent with Tapper (2005) who stated that there is no correlation between conjunctive adjuncts and good writing quality as she found that the high frequency of connectives was not found in the writings of native and non-native students of high scores.

5.2 Findings related to the second question: What is the frequency of each semantic category in KLC compared to NSC?

Table 3 below shows that the additive semantic type is the most frequent in KLC, 55\%, followed by causal $17.3 \%$, temporals $13.6 \%$, adversatives $12.1 \%$, and finally continuatives $1.7 \%$.

Table 3. Frequencies and percentages of semantic types of conjunctive adjuncts in KLC

\begin{tabular}{lll}
\hline Conjunctive relation & Frequency & $\mathbf{\%}$ \\
\hline 1- Additives & 868 & $\mathbf{5 5 \%}$ \\
2- Causals & 274 & $\mathbf{1 7 . 3} \%$ \\
3- Temporals & 216 & $\mathbf{1 3 . 6} \%$ \\
4- Adversatives & 191 & $\mathbf{1 2 . 1} \%$ \\
5- Continuatives & 28 & $\mathbf{1 . 7} \%$ \\
Total & $\mathbf{1 5 7 7}$ & $\mathbf{1 0 0} \%$ \\
\hline
\end{tabular}


Table 4 below shows the most frequent semantic types of conjunctive adjuncts used by the native speakers as compared to table 3 which shows the conjunctive adjuncts used by Kuwaiti EFL learners.

Table 4. Frequencies and percentages of semantic types of conjunctive adjuncts in NSC

\begin{tabular}{lll}
\hline Conjunctive relation & Frequency & $\mathbf{\%}$ \\
\hline 1- Additives & 382 & $\mathbf{4 1 . 7} \%$ \\
2- Adversatives & 241 & $\mathbf{2 6 . 3} \%$ \\
3- Temporals & 139 & $\mathbf{1 5 . 1} \%$ \\
4- Causals & 132 & $\mathbf{1 4 . 4} \%$ \\
5- Continuatives & 21 & $\mathbf{2 . 2} \%$ \\
Total & $\mathbf{9 1 5}$ & $\mathbf{1 0 0} \%$
\end{tabular}

Table 4 shows that the most frequent semantic types of conjunctive adjuncts used by the native speakers are additives $41.7 \%$, followed by adversatives $26.3 \%$, temporals $15.1 \%$, causals $14.4 \%$, and finally continuatives $2.2 \%$. For each semantic type a number of conjunctive adjuncts were used in KLC and NSC.

Table 5. Frequencies and percentage of additives in KLC and NSC

\begin{tabular}{lcccl}
\hline \multicolumn{1}{c}{ Additives } & KLC & \% & NSC & \% \\
\hline 1. also & 292 & 33.6 & 200 & $\mathbf{5 2 . 3}$ \\
2. for example & 174 & 20 & 38 & $\mathbf{9 . 9}$ \\
3. in addition & 172 & 19.8 & 12 & $\mathbf{3 . 1}$ \\
4. and & 55 & 6.3 & 26 & $\mathbf{6 . 8}$ \\
5. furthermore & 49 & 5.6 & 14 & $\mathbf{3 . 6}$ \\
6. moreover & 35 & 4 & 3 & $\mathbf{0 . 7 8}$ \\
7. in other words & 31 & 3.5 & 8 & $\mathbf{2}$ \\
8. thus & 20 & 2.3 & 43 & $\mathbf{1 1 . 2}$ \\
9. for instance & 15 & 1.7 & 5 & $\mathbf{1 . 3}$ \\
10. that is & 10 & 1.1 & 6 & $\mathbf{1 . 5}$ \\
11. similarly & 4 & 0.4 & 8 & $\mathbf{2}$ \\
12. or & 4 & 0.4 & 4 & $\mathbf{1 . 0 4}$ \\
13. by the way & 4 & 0.4 & - & - \\
14. in the same way & 2 & 0.2 & 3 & $\mathbf{0 . 7 8}$ \\
15. alternatively & 1 & 0.1 & 3 & $\mathbf{0 . 7 8}$ \\
16. nor & - & - & 5 & $\mathbf{1 . 5}$ \\
17. likewise & - & - & 2 & $\mathbf{0 . 5 2}$ \\
18. not only that & - & - & 1 & $\mathbf{0 . 2 6}$ \\
19. besides & - & - & $\mathbf{0 . 2 6}$ \\
Total & $\mathbf{8 6 8}$ & $\mathbf{1 0 0}$ & $\mathbf{3 8 2}$ & $\mathbf{1 0 0}$
\end{tabular}

By looking at column 2 in Table 5, it is evident that there are 16 conjunctive adjuncts used to express the additive relation in KLC and the most frequent of which are 'also' with a frequency of 292 and a percentage of $33.6 \%$, followed by 'for example' $20 \%$, 'in addition' $19.8 \%$, and 'and'

In NSC, however, there are 18 additives, the most frequent of which are 'also' with a frequency of 200 and a percentage of 52.3 followed by 'for example' $9.9 \%$ and 'in addition' $3.1 \%$ and 'and' $6.8 \%$

According to Halliday and Hasan (1976), additives express four functions, simple additives, complex additives, opposition relations and comparison relations. Simple additives are expressed by 'also' and 'and' with a percentage of $42.5 \%$ in and $6.5 \%$ respectively in both corpora. Complex additives are expressed by the conjunctives 'in addition' 
$11.5 \%$, 'furthermore' $4.6 \%$ and 'moreover' 3.5\%. Opposition relations are expressed by 'for example' $14.9 \%$, 'in other words' $2.8 \%$ and 'for instance' $1.5 \%$. Finally, comparison relation is expressed by 'similarly" $1.2 \%$

Table 6. Frequencies and percentages of adversatives in KLC and NSC

\begin{tabular}{lllll}
\hline Adversatives & KLC & \% & NSC & \% \\
\hline 1. but & 74 & 38.7 & 17 & $\mathbf{7}$ \\
2. however & 45 & 23.5 & 85 & $\mathbf{3 5 . 2}$ \\
3. on the other hand & 19 & 9.9 & 7 & $\mathbf{2 . 9}$ \\
4. though & 15 & 7.8 & 50 & $\mathbf{2 0 . 7}$ \\
5. on the contrary & 6 & 3.1 & - & - \\
6. instead & 5 & 2.6 & 7 & $\mathbf{2 . 9}$ \\
7. at the same time & 5 & 2.6 & 7 & $\mathbf{2 . 9}$ \\
8. yet & 5 & 2.6 & 24 & $\mathbf{9 . 9}$ \\
9. actually & 4 & 2 & - & - \\
10. only & 4 & 2 & - & - \\
11. rather & 3 & 1.5 & 12 & $\mathbf{4 . 9}$ \\
12. nevertheless & 2 & 1 & 5 & $\mathbf{2}$ \\
13. in fact & 2 & 1 & 18 & $\mathbf{7 . 4}$ \\
14. in spite of & 2 & 1 & - & - \\
15. at least & - & - & 4 & $\mathbf{1 . 6 5}$ \\
16. in either case & - & - & 3 & $\mathbf{1 . 2}$ \\
17. at any rate & - & - & 1 & $\mathbf{0 . 4 1}$ \\
18.despite this & - & - & 1 & $\mathbf{0 . 4 1}$ \\
Total & $\mathbf{1 9 1}$ & $\mathbf{1 0 0}$ & $\mathbf{2 4 1}$ & $\mathbf{1 0 0}$
\end{tabular}

Table 6 shows that in KLC, the adversative relation is expressed through 14 various conjunctive adjuncts, $70 \%$ of which indicate proper adversative relation through the use of 'but' with $38.7 \%$, 'however' with $23.5 \%$ and 'though' with $7.8 \%$. The conjunctive adjunct 'on the other hand' with $9.9 \%$ is used to express contrastive relation. Finally, the adjuncts 'on the contrary' with $3.1 \%$ and 'instead' $2.6 \%$ are used to express correction.

Similarly, 14 adversative conjunctive adjuncts were used in NSC, $72 \%$ of them express proper adversative relation in the adjuncts 'however' $35.2 \%$, 'though' $20.7 \%$, 'yet' $9.9 \%$ and 'but' $7 \%$. 'In fact' with $7.4 \%$ was used to express contrastive relation, 'rather' with $4.9 \%$ was used to signal correction and dismissal relation was signaled through 'in either case' $1.2 \%$ and 'at any rate' $0.41 \%$. 
Table 7. Frequencies and percentages of causals in KLC and NSC

\begin{tabular}{lcccc}
\hline Causals & KLC & \% & NSC & \% \\
\hline 1. so & 143 & 52.1 & 27 & $\mathbf{2 0 . 4}$ \\
2. therefore & 55 & 20.1 & 19 & $\mathbf{1 4 . 3}$ \\
3. then & 23 & 8.3 & 35 & $\mathbf{2 6 . 5}$ \\
4. as a result & 9 & 3.2 & 17 & $\mathbf{1 2 . 8}$ \\
5. because & 9 & 3.2 & 8 & $\mathbf{6}$ \\
6. thus & 9 & 3.2 & 10 & $\mathbf{7 . 5}$ \\
7. hence & 7 & 2.5 & 1 & $\mathbf{0 . 7 5}$ \\
8. consequently & 5 & 1.8 & 1 & $\mathbf{0 . 7 5}$ \\
9. for & 3 & 1 & - & - \\
10. for this reason & 2 & 0.7 & 2 & $\mathbf{1 . 5}$ \\
11. otherwise & 2 & 0.7 & 6 & $\mathbf{4 . 5}$ \\
12. for this purpose & 1 & 0.36 & - & - \\
13. in that case & 1 & 0.36 & - & - \\
14. in other respects & 1 & 0.36 & - & - \\
15. because of this & - & - & 4 & $\mathbf{3}$ \\
16. for that reason & - & - & 1 & $\mathbf{0 . 7 5}$ \\
17. it follows & - & - & 1 & $\mathbf{0 . 7 5}$ \\
\multicolumn{1}{c}{ Total } & $\mathbf{2 7 4}$ & $\mathbf{1 0 0}$ & $\mathbf{1 3 2}$ & $\mathbf{1 0 0}$
\end{tabular}

Table 7 shows that there are 14 different conjunctive adjuncts which express causal relation in KLC. The conjunctive adjunct 'so' occurred most frequently $52.1 \%$, followed by 'therefore' with $20.1 \%$, 'then' with $8.3 \%$, 'as a result' which expressed result relation with $4.7 \%$. Finally, the conjunctive adjunct 'because' was used $3.2 \%$ to express reversed causality.

In NSC, there are 13 various conjunctive adjuncts which express causal relation. The most frequent ones are 'then' $26.5 \%$, 'so' $20.4 \%$, 'therefore' $14.3 \%$, 'thus' $7.5 \%$ and 'because of this' $3 \%$ which express general causality. It was found that 'as a result' was used $12.8 \%$ to express result relation, 'because' was used $6 \%$ to express reversed causality, and 'otherwise' was used $4.5 \%$ to express reversed polarity. 
Table 8. Frequencies and percentages of temporals in KLC and NSC

\begin{tabular}{|c|c|c|c|c|}
\hline Temporals & KLC & $\%$ & NSC & $\%$ \\
\hline 1. then & 65 & 30 & 34 & 24.4 \\
\hline 2. here & 23 & 10.6 & 40 & 28.7 \\
\hline 3. finally & 23 & 10.6 & 18 & 12.9 \\
\hline 4. firstly & 22 & 10.1 & 1 & 0.7 \\
\hline 5. first & 20 & 9.25 & 11 & 7.9 \\
\hline 6. secondly & 14 & 6.4 & - & - \\
\hline 7. in conclusion & 14 & 6.4 & 1 & 0.7 \\
\hline 8. after that & 9 & 4.1 & - & - \\
\hline 9. second & 5 & 2.3 & 3 & 2.1 \\
\hline 10. at the same time & 5 & 2.3 & 7 & 5 \\
\hline 11. briefly & 3 & 1.3 & - & - \\
\hline 12. previously & 3 & 1.3 & 4 & 2.8 \\
\hline 13. before that & 2 & 0.9 & - & - \\
\hline 14. to sum up & 2 & 0.9 & - & - \\
\hline 15. at first & 2 & 0.9 & 1 & 0.7 \\
\hline 16. meanwhile & 1 & 0.46 & 3 & 2.1 \\
\hline 17. lastly & 1 & 0.46 & 1 & 0.7 \\
\hline 18. at this point & 1 & 0.46 & 7 & 5 \\
\hline 19. in short & 1 & 0.46 & 1 & 0.7 \\
\hline 20. next & - & - & 7 & 5 \\
\hline Total & 216 & 100 & 139 & 100 \\
\hline
\end{tabular}

Table 8 shows that 19 different conjunctive adjuncts occurred in KLC to express temporal relation. The most frequent ones were 'then' $30 \%$, 'first' 9.25\%, 'firstly' $10.1 \%$ and 'secondly' $6.4 \%$. They were used to indicate sequential relation. The conjunctive adjunct 'here' occurred $10.6 \%$ to express the relation of 'Here and Now'. The conjunctive adjuncts 'finally' $10.6 \%$ and 'in conclusion' $6.4 \%$ were used to indicate conclusive relation.

In NSC, 15 various conjunctive adjuncts were used to express temporal relation. The most frequent of which were 'here' $28.7 \%$ used to express 'Here and Now' relation. Another conjunctive used to express the same relation is 'at this point' 5\%. The other less frequent adjuncts were 'then' $24.4 \%$, 'first' $7.9 \%$, and 'next' $5 \%$. The conjunctive adjunct 'finally' occurred $12.9 \%$ to express conclusive relation. The other conjunctive adjuncts are not as frequent as shown in Table 9.

Table 9. Frequencies and percentages of continuatives in KLC and NSC

\begin{tabular}{lllll}
\hline Continuatives & KLC & $\mathbf{\%}$ & NSC & \% \\
\hline 1. now & 19 & 67.8 & 10 & $\mathbf{4 7 . 6}$ \\
2. of course & 1 & 3.5 & 6 & $\mathbf{2 8 . 5}$ \\
3. after all & - & - & 3 & $\mathbf{1 4 . 2}$ \\
4. well & - & - & 1 & $\mathbf{4 . 7}$ \\
5. anyway & 4 & 14.2 & 1 & $\mathbf{4 . 7}$ \\
6. surely & 4 & 14.2 & - & - \\
Total & $\mathbf{2 8}$ & $\mathbf{1 0 0}$ & $\mathbf{2 1}$ & $\mathbf{1 0 0}$
\end{tabular}

Table 9 shows that the number of the continuatives is not large in either KLC or NSC. They are only six items, namely, 'now, of course, after all, well, anyway, and surely'. In KLC, only four continuatives were used. The most 
frequent one was 'now' with $67.8 \%$. 'anyway' and 'surely' $14.2 \%$ each. In NSC, five continuatives were used, the most frequent ones are 'now' $47.6 \%$, 'of course' $28.5 \%$ and 'after all' $14.2 \%$.

From the above it is apparent that the most frequent semantic type of conjunctive adjuncts is the additive relation in KLC and in NSC. But there was an evident overuse of the additives in KLC as shown by the high percentage 55\%. The causal relations ranked second with 17.3\%. This agrees with Fakhra (2009) who found that Syrian students used almost twice as many conjunctive adjuncts in comparison to the British students, particularly causal and additives adjuncts. In addition, these findings are in line with Ishikawa (2009) who found that Asian non-native speakers overused additive conjunctive adjuncts and underused temporals.

Adversatives were used more frequently in NSC 26.3\% than in KLC 12.1\%. Consequently, Kuwaiti EFL learners did not use adversatives as frequently. Some non-native speakers use adversatives in a way similar to native speakers. Tapper (2005) found that Swedish used contrastive, which is equal to adversative, followed by the resultative, clarifying and finally additive relations.

The frequency of temporal relations was almost the same in KLC and NSC. Finally, the continuatives were used less than the other semantic relations in the corpora and this may be attributed to the fact that the number of continuatives is relatively smaller and it is mainly used in conversation.

In both corpora, simple additives were used to signal the additive relation with slightly more use in the writings of the Kuwaiti EFL learners. In brief, both groups learners used 'also' which, in particular, is more frequently used by native speakers. This ties in well with Fakhra (2009) who argued that 'also' was the most frequent additive conjunctive adjunct used in all the corpora; yet, it was not always effectively employed, as some students tended to insert it repeatedly or unnecessarily between sentences. In addition, the additive 'and' was frequently used by both groups of learners though 'and' is considered improper to start a sentence with and connect it to a previous one.

On the other hand, the excessive use of 'and' can be attributed to first language interference, as in Arabic writing it is a quite common sentence/clause connector (Hinkel, 2001). One of the examples of this interference is the study of Abu Sharkh (2012) who found that additive adjuncts in particular were overused by the beginners and intermediate learners.

Table 6 also showed that the native speakers use various additives to express the apposition relation such as 'for instance, thus and for example' while the Kuwaiti EFL learners mainly used 'for example' to show this relation. The Kuwaiti EFL learners frequently used the complex conjunctive adjuncts as 'in addition' and 'moreover' and this is not frequently evident in the writings of the native speakers. Other additive relations such as comparison are not frequent in either KLC or NSC.

It was found that in NSC the focus was on using adversative conjunctive adjuncts such as 'however, though, yet and but'. The focus on using 'however' confirms what Biber et al (1999) reported that in academic prose, in particular 'however' is found to be one of the conjunctive adjuncts that occurs with notable frequencies mainly to mark contrast. Generally speaking, this relation was underused in KLC and instead the conjunctive adjuncts 'but' and 'however' were used to express proper adversative relation.

With regard to causals, which were overused by the Kuwaiti EFL learners, it was found that the main conjunctive adjuncts used to express general causality in KLC were 'so' and 'therefore'. These were also overused by the native speakers as well. But, this is not in line with Biber et al (1999) who suggested that "so and then are found to be very common in conversation; on the other hand, then, therefore, thus, and hence were found moderately common in academic prose" (p. 886). In NSC, it was found that the conjunctive adjuncts 'then' and 'thus' were used often to indicate the general causality. Conjunctive adjuncts such as 'because' were used in KLC and NSC to indicate reversed polarity.

With respect to temporals, the Kuwaiti EFL learners used 'then, first, firstly, secondly and second' to indicate sequential relation but this was not frequently used in NSC except 'then' which was used frequently. In addition the use of the conjunctive adjunct 'here' to indicate 'Here and Now' relation was emphasized in NSC, whereas 'finally' and 'in conclusion' were equally emphasized in KLC to indicate conclusive relation. This is consistent with Fakhra (2009) who found that in the corpus of Syrian students of English the temporal conjunctive, 'finally' was used with the highest percentage, followed by 'then', with the first indicating a 'conclusive' relation and the second a 'sequential' one. But, in the writings of the native speakers, they focus was mainly on using 'finally' only.

Five continuatives were used in NSC in comparison to only four in KLC which constitute the fewest semantic relations of conjunctive adjuncts in the writings of both groups. The most frequent conjunctive adjunct in NSC was 'now', followed by 'of course' and finally 'after all'. In KLC, the most frequent continuative was 'now' followed 
by 'anyway', 'surely' and 'of course'. In both KLC and NSC the most frequent CA was 'now' in which signals the opening of a new stage in the communication

5.3 Findings related to the third question: What are the overused and underused conjunctive adjuncts in KLC compared to those used in NSC?

The overused and underused conjunctive adjuncts in KLC and NSC were measured on the basis of the occurrence ratios of conjunctive adjuncts in KLC against the occurrence ratios in NSC. In other words, the difference between the use of conjunctive adjuncts in KLC and NSC was found out through calculating the percentage of individual conjunctive adjuncts in KLC and the percentage of the same adjuncts in NSC.

Table 10. The overused conjunctive adjuncts in KLC and NSC

\begin{tabular}{llllll}
\hline Overused CAs & KLC & \% & NSC & \% & D* \\
\hline 1. in addition & 172 & 10.9 & 12 & 1.3 & $\mathbf{9 . 6}$ \\
2.for example & 174 & 11 & 38 & 4.15 & $\mathbf{6 . 8 5}$ \\
3. so & 143 & 9 & 27 & 2.9 & $\mathbf{6 . 1}$ \\
4. but & 74 & 4.69 & 17 & 1.85 & $\mathbf{2 . 8 4}$ \\
5. moreover & 35 & 2.2 & 3 & 0.32 & $\mathbf{1 . 8 8}$ \\
6.furthermore & 49 & 3.1 & 14 & 1.53 & $\mathbf{1 . 5 7}$ \\
7. therefore & 55 & 3.48 & 19 & 2 & $\mathbf{1 . 4 8}$ \\
8. firstly & 22 & 1.39 & 1 & 0.1 & $\mathbf{1 . 2 9}$ \\
9.in other words & 31 & 1.96 & 8 & 0.87 & $\mathbf{1 . 0 9}$ \\
\hline
\end{tabular}

\section{$* D=$ difference value}

Table 10 shows that Kuwaiti students overused certain conjunctive adjuncts such as 'in addition, 172, for example 174, so 143 and but 74'. The native speakers' of English overused for example 38, so 27, therefore 19, and but. From Table 11 it is clear that the frequency of individual Conjunctive adjuncts is higher in KLC than in NSC, for instance in addition occurred 172 in KLC and 12 in NSC and for example occurred 174 in KLC and 38 times in NSC and so occurred 143 in KLC and 27 in NSC. Some of these conjunctive adjuncts are overused by other non-native speakers of English. It was found that the conjunctive adjunct 'moreover' is overused by French learners (Granger and Tyson, 1996). Also, Ishikawa (2009) found that Japanese and Chinese learners of English overuse 'moreover', 'also', 'anyway', 'only', and 'now'. In addition, the conjunctive adjuncts 'so' and 'but' were overused by Hong Kong students (Bolton, Nelson and Hung, 2003). Kuwaiti learners of English overused 'so, but' and so did Syrian learners of English as confirmed by Fakhra (2009) in her research. One of the reasons responsible for this overuse could be attributed to the interference from Arabic (Hinkel, 2001). For example, 'so' equals the Arabic conjunctive (faa) and this conjunctive is one of the main conjunctives that are used to connect sentences in Arabic.

Table 11. The underused conjunctive adjuncts in KLC and NSC

\begin{tabular}{llllll}
\hline Underused CA & KLC & \% & NSC & \% & D* \\
\hline 1. however & 30 & 1.90 & 50 & 9.28 & $\mathbf{- 6 . 4 3}$ \\
2. though & 15 & 0.95 & 45 & 5.46 & $\mathbf{- 4 . 5 1}$ \\
3. thus & 20 & 1.26 & 43 & 4.69 & $\mathbf{- 3 . 4 3}$ \\
5. here & 23 & 1.45 & 40 & 4.3 & $\mathbf{- 2 . 8 5}$ \\
6. then & 23 & 1.45 & 35 & 3.8 & $\mathbf{- 2 . 3 5}$ \\
7. yet & 5 & 0.317 & 24 & 2.6 & $\mathbf{- 2 . 2 8}$ \\
8. in fact & 2 & 0.126 & 18 & 1.96 & $\mathbf{- 1 . 8 3}$ \\
9. as a result & 9 & 0.57 & 17 & 1.85 & $\mathbf{- 1 . 2 8}$ \\
\hline
\end{tabular}

\section{$* D=$ difference value}

Table 11 shows that Kuwaiti students underused certain conjunctive adjuncts such as 'as a result' 9 times, 'in fact' twice, ' yet', 5 times 'then', 23 times. The native speakers of English underused the same conjunctive adjuncts but with different frequencies as shown in Table 12. Kuwaiti students underused some conjunctive adjuncts such as 
'however' 30, 'though' 15, and 'yet' 5'. These are used to express adversative relation. It seems that because of their overuse of 'but', they underused these conjunctive adjuncts

The conjunctive adjuncts underused in KLC are the most frequently used in the English language as found by Biber et al (1999). This finding is in line with what Granger and Tyson (1996) reported in their research that 'however', though, yet, then' are underused in the French corpus. Also, Ishikawa (2009) found that 'instead, rather, finally, lastly, eventually' are underused. Again Fakhra (2009) found that Syrian students underused 'however', and 'yet'. Granger and Tyson (1996) pointed to the reasons of this improper use of conjunctive adjuncts and underuse and stated:

Even at a reasonably advanced level, connectors are difficult to master, we have seen that French learner connector usage differs widely from that of their native speaker counterparts: this is due to an inability to differentiate stylistically, insufficient knowledge of semantic restrictions placed on individual connectors, and inexperience in manipulating connectors within the sentence structure (pp. 24-25)

Granger and Tyson (1996) also suggested solutions to the problem of overuse and underuse of such forms by stating that it is important to teach students that conjunctive adjuncts in English should not be used as 'stylistic enhancers' but should be thought of as higher-level discourse units. In addition, they stated "it is necessary to place more emphasis on how to use connectors, laying stress on examining their use in authentic texts" (p. 25). They agreed with Crewe (1990) who argues "misleading lists of so-called interchangeable connectors often found in textbooks should be avoided at all costs"(p. 25).

Tanko (2004) also suggested that teachers should teach "learners why, when, and how to use connectors so that their written output approximates the norms of native texts and this is not an easy undertaking" (p. 159). There are various linguistic and methodological factors that make the acquisition and appropriate use of connectors difficult for ESL and EFL writers. He argued that

The sources of difficulty related to the use of connectors are diverse and rooted in their discourse-organizing function, grammatical, semantic, and morphological attributes, and also in shortcomings in the techniques employed to teach these devices. 2004 p, 159)

\section{Conclusion}

The corpus-based approach which was used to study the use of conjunctive adjuncts in the writings of native and non native university students can be viewed as a major contribution of this research. The corpus approach, according to Bennett (2010) is comprised of four major characteristics. First, it is empirical, analyzing the actual patterns of language use in natural texts. Corpora consist of authentic language and are composed of a variety of texts taken from fiction, nonfiction, magazines, newspapers, academic papers, radio broadcasts, business meetings, class lectures. In short, any real life situation in which any linguistic communication takes place can form a corpus. Second, it utilizes a large and principled collection of naturally occurring texts as the basis for analysis which implies that the researcher can work with a written corpus, a spoken corpus or academic spoken corpus, to mention only a few. Third, it makes extensive use of computers for analysis. In addition to storing corpora, computers help analyze the language in a corpus through the use of a software called concordancing program. Without a computer, nobody whether a teacher or researcher can effectively use corpora or analyze them. Finally, it depends on both quantitative and qualitative analytical techniques in the sense that quantitative results obtained from language corpora are qualitatively analyzed and interpreted through the use of language experts' intuition. Qualitative analysis of the results generally involves examining the language item under investigation, whether the frequency of a certain collocation, or the frequency of adverbs of degree such as very, rarely, quite and really in the speech or writings of native or non-native speakers.

The other contribution of this research is evident to teachers who can use corpus based approach not only as a research tool but also as a teaching tool which can stimulate and motivate students to better learn English. It can undoubtedly help EFL teachers to identify student errors and explain the sources of these errors, whether they are attributed to the first language or the structures of the target language itself; besides, it can help learners to understand commonalities in usage as well as errors. Teachers are therefore encouraged to get an idea of how to apply corpora in EFL contexts. This is exactly what Bennett asserted in these few lines:

"Knowledge of what corpus linguistics is and is not, questions that corpora can answer, the corpus approach, types of corpora and concordancing programs, and how to create corpus-designed activities all help to provide a solid foundation for understanding the application of corpus linguistics.” (2010, p.22)

To conclude, it is recommended that a study on conjunctive adjuncts, with a larger corpus-based data be conducted in the Kuwaiti context to confirm the findings of the study. It is also recommended that a study on the use of conjunctive adjuncts be conducted on EFL secondary school Kuwaiti students to trace the development of these forms in later stages. Finally, another study is recommended to detect the use of conjunctive adjuncts in different 
types of writing styles such as narrative, and argumentative to find out the extent to which this use varies from one style to another.

\section{Acknowledgements}

Note: The authors wish to express their sincere gratitude to Prof Najib Al-Shehabi of the Arab Open University in Kuwait for recommending the use of the software MonoConc Pro which proved to be an excellent means for analyzing the conjunctive adjuncts in naturally occurring data. The authors also wish to thank two anonymous readers for their comments and advice

\section{References}

Abu Sharkh, B. (2012). Cohesion and coherence in the essay writing of Palestinian college students. (Unpublished MA Thesis, Hebron University)

Altenberg, B \& Tapper, M (1998). The use of adverbial connectors in advanced Swedish learner's written English in Granger, S (ed.) Learner English on Computer. (pp.80-93) London: Longman.

Bacha, N. \& Hanania, E. (1980). Difficulty in learning and effectiveness of teaching transitional words: A study of Arabic speaking university students. TESOL Quarterly, 14 (2), 251-254. http://dx.doi.org/10.2307/3586323

Bennett, Gena R. (2010) Using corpora in the language learning classroom: Corpus linguistics for teachers. Detroit: Michigan University Press

Biber, D., Johansson, S., Leech, G., Conrad, S., \& Finegan, E. (Eds.) (1999). Longman grammar of spoken and written English. Harlow, UK: Pearson Education Limited.

Bloor, T. \& Bloor, M. (1995). The functional analysis of English: A hallidayan approach. London and New York: Arnold.

Bolton, K. Nelson, G. \& Hung, J. (2003). A corpus-based study of connectors in student writing. International Journal of Corpus Linguistics, 7 (2), 165-182. http://dx.doi.org/10.1075/ijcl.7.2.02bol

Crewe, W. J. (1990). The illogic of logical connectives. ELT Journal, 44(4), 316-325. http://dx.doi.org/10.1093/elt/44.4.316

Eggins, S. (2004). Introduction to systemic functional linguistics. New York: Continuum International Publishing Group.

Fakhra, A. (2009). Relative clauses and conjunctive adjuncts in Syrian university writing in English. (Doctoral dissertation, the University of Warwick). [Online] Available: http://go.warwick.ac.uk/wrap/2753

Granger, S. \& Tyson, S. (1996). Connector usage in the English essay writing of native and non-native EFL speakers of English. World Englishes, 15(1), 17-27. http://dx.doi.org/10.1111/j.1467-971X.1996.tb00089.x

Halliday, M. A. K. \& Hasan, R. (1976). Cohesion in English. London: Longman.

Hinkel, E. (2001). Matters of cohesion in L2 academic texts. Applied Language Learning, 12 (2), 111-132.

Ishikawa, S. (2009). A corpus-based study on Asian learners' use of English linking adverbials. Themes in Science and Technology Education, 3 (1-2), 139-157

Khalil, A. (1989). A study of cohesion and coherence in Arab EFL college students' writing. System, 17, (3) 359-371. http://dx.doi.org/10.1016/0346-251X(89)90008-0

Kuwaileh, A \& Shoumali, A. (2000). Writing errors: A study of the writing ability of Arab learners of Academic English and Arabic at university. Language, Culture and Curriculum, 13 (2), 174-1831

Patanasorn, A. (2010). The use of linking adverbials in the argumentative essays of Thai EFL learners. KKU Research Journal, 5 (78), 751-767.

Reppen, R. (2001). Review of MonoConc Pro and Wordsmith tools. Language Learning and Technology, 5 (3), 32-36. [Online] Available: http://llt.msu.edu/vol5num3/review4/

Tanko, G. (2004). The use of adverbial connectors in Hungarian university students' argumentative essays. In J. M. Sinclair (Ed.), How to use corpora in language teaching (pp.157-184). Philadelphia: John Benjamins Publishing Company. http://dx.doi.org/10.1075/scl.12.13tan

Tapper, M. (2005). Connectives in advanced Swedish EFL learners' written English: Preliminary results. The Department of English: Working Papers in English Linguistics, 5, 116-144. 
Appendix A

Summary Table of Conjunctive Relation

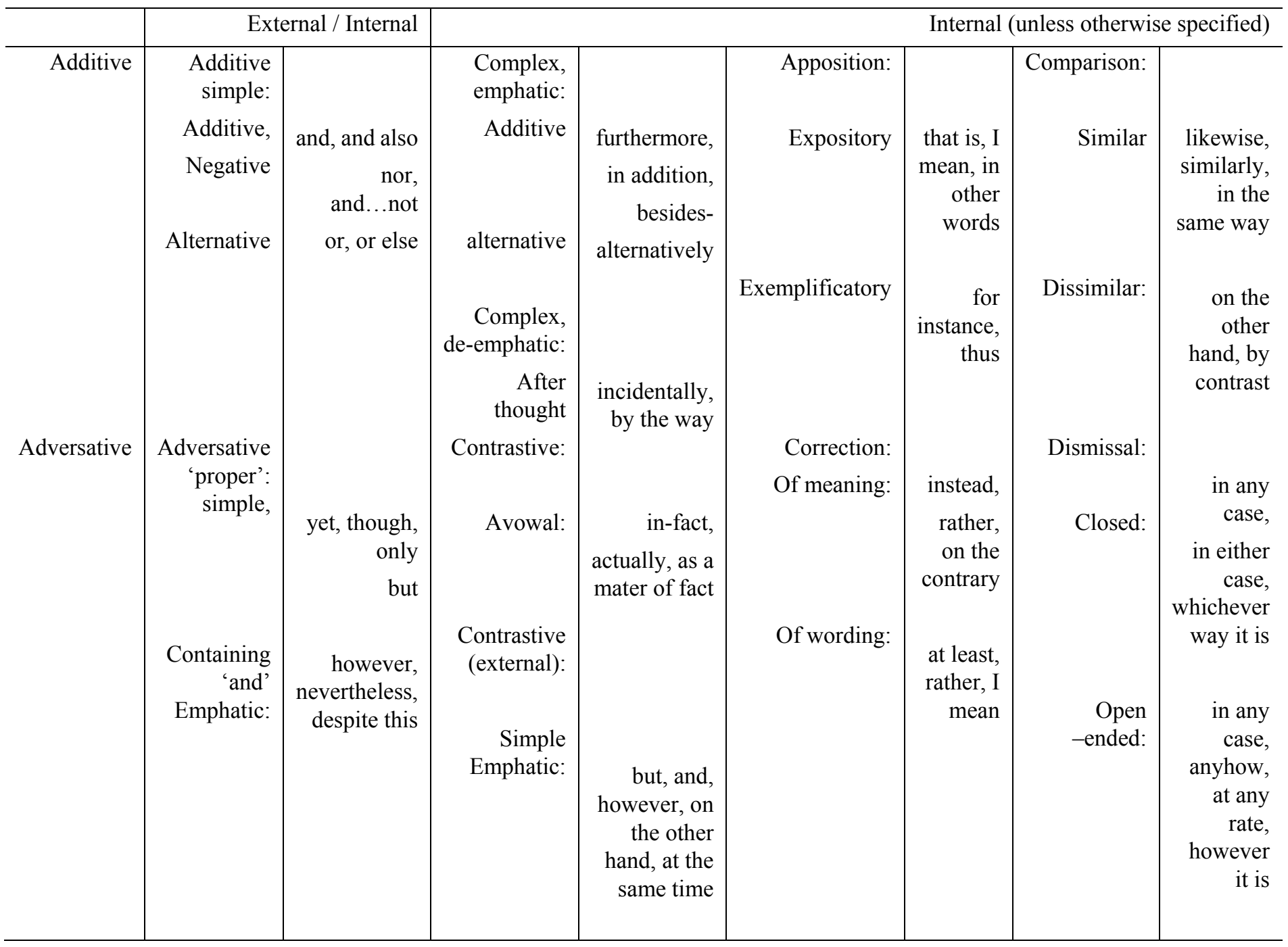




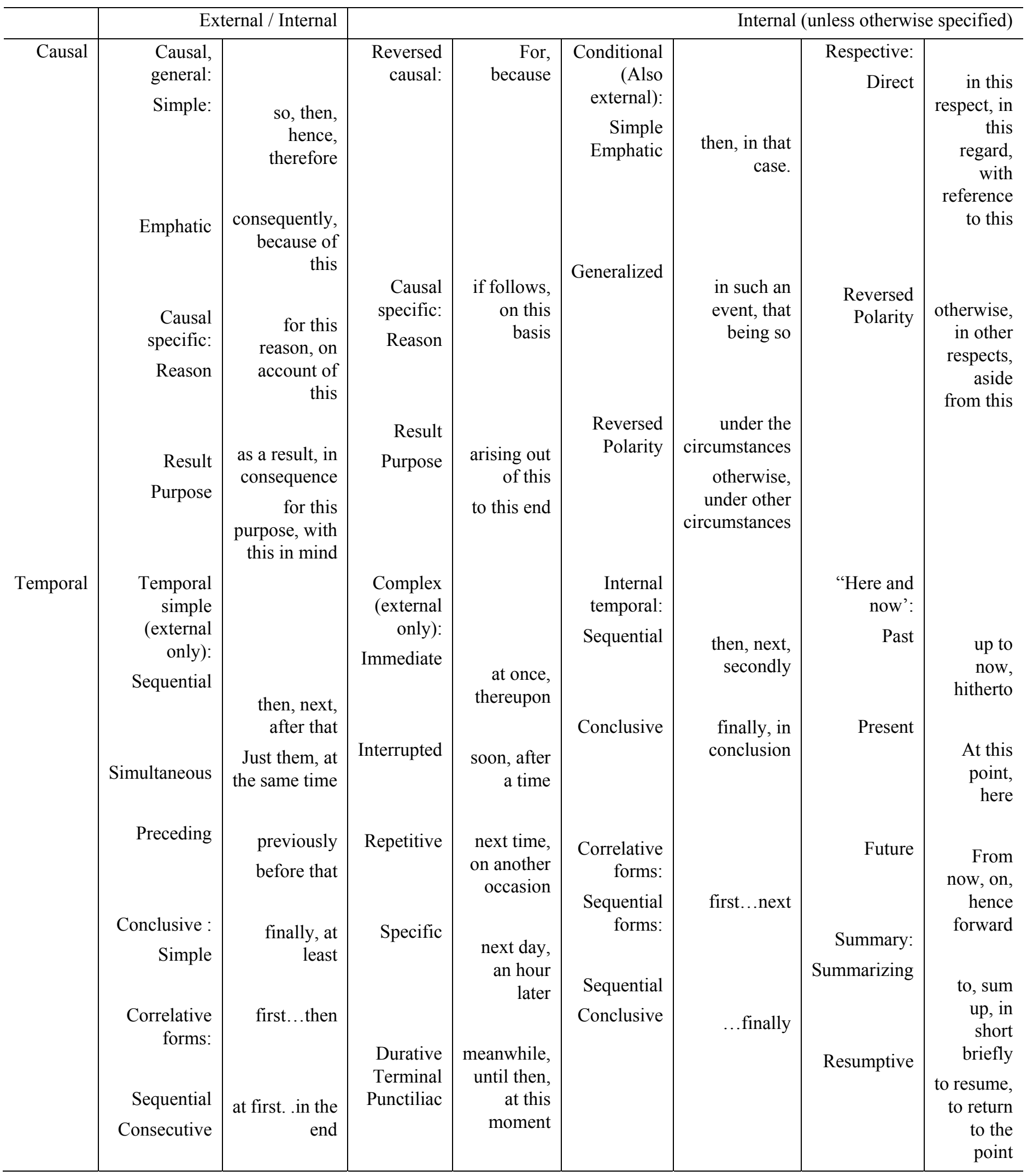

